\title{
Successful management of secondary postpartum haemorrhage due to post caesarean wound dehiscence with uterine artery embolisation
}

\author{
Pushplata Kumari, Anuja Abraham, Annie Regi, Preethi Navaneethan*
}

Department of Obstetrics and Gynaecology, Christian Medical College and Hospital, Vellore, Tamil Nadu, India

Received: 31 March 2021

Accepted: 01 May 2021

\section{*Correspondence:}

Preethi Navaneethan,

E-mail: rnpreethi@yahoo.co.in,

Copyright: (C) the author(s), publisher and licensee Medip Academy. This is an open-access article distributed under the terms of the Creative Commons Attribution Non-Commercial License, which permits unrestricted non-commercial use, distribution, and reproduction in any medium, provided the original work is properly cited.

\begin{abstract}
Caesarean scar dehiscence usually presents as secondary postpartum haemorrhage (PPH) with persistent spotting, fever or abdominal distension. The known management are either with laparotomy followed by resuturing of the scar or hysterectomy. However, most of the patient ultimately undergo hysterectomy due to the persistence of vaginal bleeding. We presented a case of PPH secondary due to scar dehiscence post lower segment caesarean section (LSCS), which was successfully managed with bilateral uterine artery embolization without hysterectomy. Our patient presented with vaginal bleeding on 16th post LSCS day and USG showed presence of a hyperechoic area measuring $5 \times 6 \mathrm{~cm}$ more towards the right angle suggestive of the scar dehiscence with hematoma. She underwent bilateral uterine artery embolization and had decreased in the vaginal bleeding with gradual regression in the size of the hematoma over a period of time. Radiological intervention with bilateral uterine artery embolization (UAE) can be used as one of the modalities of management for the hemodynamically stable patient.
\end{abstract}

Keywords: LSCS, UAE (uterine artery embolization), PVC (polyvinyl), USG (ultrasonography)

\section{INTRODUCTION}

Secondary PPH after caesarean section occurs in 1:365 women. ${ }^{1}$ Although rare, uterine scar dehiscence may present with the complication of secondary $\mathrm{PPH}$, endomyometritis, localized/generalized peritonitis or sepsis. These complications managed either with laparotomy and resuturing of the scar or hysterectomy. Bilateral uterine or hypogastric artery embolization is an alternative measure to control the bleeding in women with either pseudoaneurysm or AV malformation. The reported success rate of this approach is $42 \%$ due to extensive collateral circulation. ${ }^{2,3}$ Most of the patient with scar dehiscence ultimately undergo hysterectomy due to the persistence of vaginal bleeding. ${ }^{4}$ We presented a case of secondary PPH due to scar dehiscence post LSCS successfully managed with bilateral uterine artery embolization.

\section{CASE REPORT}

A 32 year old female presented on 18th day postcaesarean delivery with low-grade fever and excessive bleeding per vagina since last 6-7 days. The fever was low grade occasionally associated with chills and rigour. She was changing 5-6 pad per day. She was multigravida with 2 prior LSCS and had undergone LSCS with bilateral tubectomy in another hospital for placenta previa with intrauterine death at 32 weeks of gestational age. Intraoperatively, she has transfused two units of the packed cell. The postoperative period was uneventful and was discharged on the 5th day of surgery.

On presentation, she had a low-grade fever and no tachycardia. There was lower abdominal tenderness but no guarding or rigidity. The abdominal wound was unremarkable and uterus was involute to 20 weeks. On pelvic examination, lochia was healthy, uterus deviated to 
one side and os closed. There was the presence of fresh bleeding from the vagina.

Bedside abdominal ultrasound uterus to be postpartum with minimal clots in the endometrial cavity. The lower uterine segment near the incision was ballooned out due to the presence of a hyperechoic area measuring $5 \times 6 \mathrm{~cm}$ more towards the right angle suggestive of the scar dehiscence with hematoma (Figure 1). Bilateral ovaries were normal. On investigation, the haemoglobin was 8 $\mathrm{gm} / \mathrm{dl}$. Her platelets and other coagulation profile were within the normal limit.

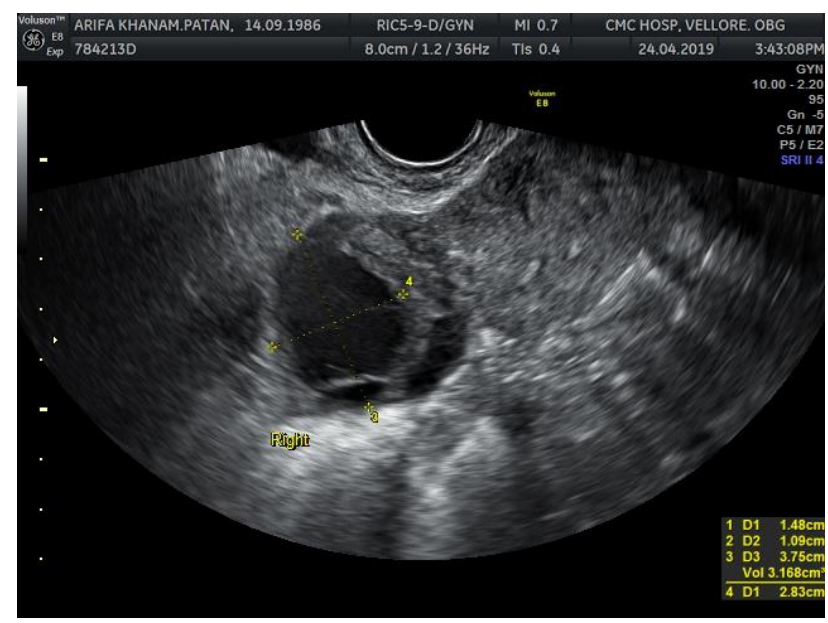

Figure 1: Hyperechoic area more towards the right angle suggestive of the scar dehiscence with hematoma.

As she was hemodynamically stable and the patient not willing for surgical intervention. The option of conservative management with pelvic angiogram with bilateral UAE was considered. The pigtail catheter was used to flush the cobra catheter in the internal iliac artery. Angiogram showed bilateral hypertrophied uterine artery which was selectively cannulated and embolized with PVC particle till the achievement of stasis.

Post-procedure she was intensely monitored and she remained stable. However, on 3rd day post embolization, she developed a high-grade fever with no localization feature. Blood parameters were sent and were with the normal limit. She received parental antibiotics for 5 days. Fever settled and there was no bleeding per vagina during her observational period. Repeat USG done on day 5 before discharge showed the uterine cavity with an endometrial thickness of $12 \mathrm{~mm}$, the size of the hematoma was $4.7 \times 3.3 \mathrm{~cm}$ (Figure 2 and 3 ). She was discharged with the recommendation of weekly follow up in the outpatient unit. She came for follow up every two weeks for 2 months. There was no history of fever and minimal spotting per vagina. Serial USG showed a decrease in the size of hematoma from $2.8 \times 2.6 \mathrm{~cm}$ to $1.4 \times 1.0 \mathrm{~cm}$. Further visit hematoma was not visualized at all.

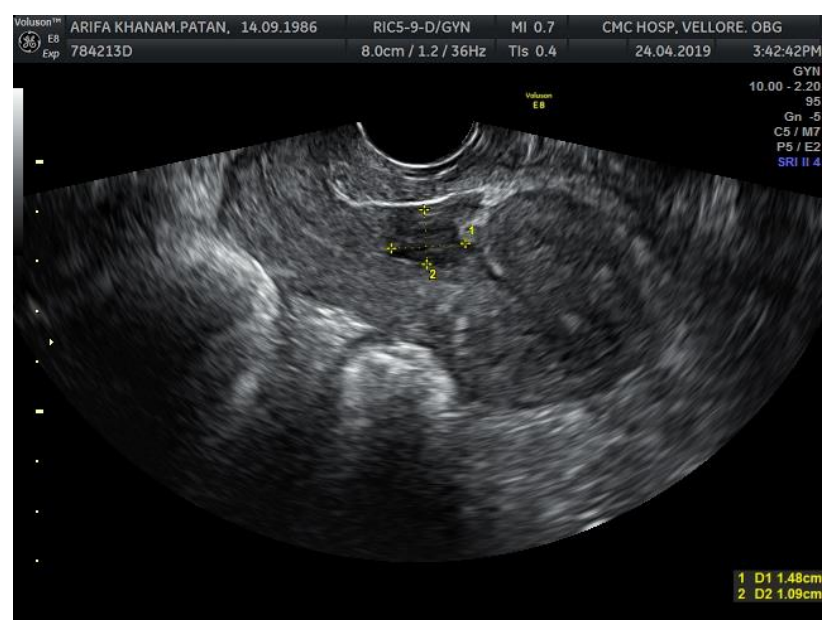

Figure 2: Area after embolization.

\section{DISCUSSION}

The incidence of scar dehiscence during labour worldwide is around $0.6 \%$. The usual cause for scar dehiscence is previous lower segment caesarean section, classical caesarean section, congenital anomaly, inappropriate oxytocic administration or abnormal placentation.

The patient presents with post-partum haemorrhage, generalized or localized peritonitis. Some diagnosed immediately after childbirth and some present late after about 2-4 weeks of delivery. Identification of this condition depends on high clinical suspicion. Radiological sign-on 2D USG or CT scan is not specific and has poor correlation. ${ }^{4}$ However, the presence of free fluid, bladder flap hematoma more than $5 \mathrm{~cm}$, bowel distention is considered as a nonspecific feature of scar dehiscence. ${ }^{5}$

Exploratory laparotomy is considered one of the most important methods of diagnosis and treatment of uterine scar dehiscence. Conservative surgery as debridement of the necrotic tissue with hematoma evacuation and resuturing is usually done. There are reports of conservative treatment even in the presence of infection. Peripartum hysterectomy is performed as a treatment of choice in about $6 \%$ of patient with postoperative scar dehiscence associated with severe cellulitis or sepsis.

Conservative management with radiological intervention is one of the modalities of management in stable patient with no evidence of infection. This way the morbidity associated with surgery and prolonged hospital stay can be decreased.

Transcatheter arterial embolization has been first recognized in 1960 as a method to control haemorrhage, and since then has been used to control pelvic haemorrhage due to malignancy, trauma and radiation. ${ }^{6,7}$ Recently, this technique has been used successfully in the control of $\mathrm{PPH} .^{8-10}$ UAE has several advantages, 
including easy identification of the bleeding site, preservation of the uterus and fertility and decreased rebreeding from collaterals with more distal occlusion of the bleeding vessels.

A recent review by Badaway and colleagues included 138 cases of PPH treated by arterial embolization, with a success rate of $94.9 \%$ and a complication rate of $8.7 \% .{ }^{9}$ In this series, seven cases required hysterectomy as a result of the failure of embolization. Some studies have shown the resumption of menstruation and pregnancies after the procedure the overall complication rate of $8.7 \% .^{11}$ The commonest complication is low-grade fever, pelvic infection, groin hematoma, iliac artery perforation, transient buttock ischemia, transient foot ischemia and bladder gangrene. ${ }^{8,9}$ As there is no evidence on the impact in the next pregnancy after embolization for scar dehiscence. This procedure can be clinically applicable for women not desirous for the next pregnancy and keen to preserve the uterus.

\section{CONCLUSION}

Secondary PPH due to uterine scar dehiscence can be diagnosed with a high index of clinical suspicion. Ultrasonography remains one of the best tools to confirm the diagnosis. Radiological intervention with bilateral uterine artery embolization can be used as one of the conservative methods for hemodynamically stable patient.

Funding: No funding sources

Conflict of interest: None declared

Ethical approval: Not required

\section{REFERENCES}

1. Wagner MS, Bédard MJ. Postpartum uterine wound dehiscence: a case report. J Obstet Gynaecol Can JOGC. 2006;28(8):713-5.

2. Clark SL, Phelan JP, Yeh SY, Bruce SR, Paul RH. Hypogastric artery ligation for obstetric hemorrhage. Obstet Gynecol. 1985;66(3):353-6.
3. Touboul C, Badiou W, Saada J, Pelage JP, Payen D, Vicaut E, et al. Efficacy of selective arterial embolisation for the treatment of life-threatening post-partum haemorrhage in a large population. PloS One. 2008;3(11):3819.

4. Brown BJ, Heaston DK, Poulson AM, Gabert HA, Mineau DE, Miller FJ. Uncontrollable postpartum bleeding: a new approach to hemostasis through angiographic arterial embolization. Obstet Gynecol. 1979;54(3):361-5.

5. Rodgers SK, Kirby CL, Smith RJ, Horrow MM. Imaging after cesarean delivery: acute and chronic complications. Radiogr Rev Publ Radiol Soc N Am Inc. 2012;32(6):1693-712.

6. Ring EJ, Athanasoulis C, Waltman AC, Margolies $\mathrm{MN}$, Baum S. Arteriographic management of hemorrhage following pelvic fracture. Radiology. 1973;109(1):65-70.

7. Miller FJ, Mortel R, Mann WJ, Jahshan AE. Selective arterial embolization for control of hemorrhage in pelvic malignancy: femoral and brachial catheter approaches. AJR Am J Roentgenol. 1976;126(5):1028-32.

8. Vedantham S, Goodwin SC, McLucas B, Mohr G. Uterine artery embolization: an underused method of controlling pelvic hemorrhage. Am J Obstet Gynecol. 1997;176(4):938-48.

9. Badawy SZ, Etman A, Singh M, Murphy K, Mayelli T, Philadelphia M. Uterine artery embolization: the role in obstetrics and gynecology. Clin Imaging. 2001;25(4):288-95.

10. Heaston DK, Mineau DE, Brown BJ, Miller FJ. Transcatheter arterial embolization for control of persistent massive puerperal hemorrhage after bilateral surgical hypogastric artery ligation. AJR Am J Roentgenol. 1979;133(1):152-4.

11. Stancato-Pasik A, Mitty HA, Richard HM, Eshkar N. Obstetric embolotherapy: effect on menses and pregnancy. Radiology. 1997;204(3):791-3.

Cite this article as: Kumari $\mathrm{P}$, Abraham A, Regi A, Navaneethan P. Successful management of secondary postpartum haemorrhage due to post caesarean wound dehiscence with uterine artery embolisation. Int J Reprod Contracept Obstet Gynecol 2021;10:2534-6. 